\title{
Refinement of the locus for autosomal recessive cone-rod dystrophy (CORD8) linked to chromosome 1q23-q24 in a Pakistani family and exclusion of candidate genes
}

\author{
Muhammad Ismail · Aiysha Abid · Khalid Anwar · \\ S. Qasim Mehdi · Shagufta Khaliq
}

Received: 27 April 2006/Accepted: 5 June 2006/Published online: 3 August 2006

(C) The Japan Society of Human Genetics and Springer-Verlag 2006

\begin{abstract}
Cone-rod retinal dystrophy (CORD) characteristically leads to early impairment of vision due to the simultaneous involvement of both cone and rod photoreceptor cells. Several loci/genes have been identified for CORD, including the cone-rod dystrophy (CORD8) locus [OMIM\#605549] identified for a Pakistani family. All members of this family underwent detailed clinical re-examination to determine the nature of the dystrophy. All affected individuals suffered from bilateral CORD8 with an autosomal recessive mode of inheritance. The CORD8 locus, mapped on chromosome 1q12-q24, consisted of a very large critical disease region of $21 \mathrm{cM}$. Analysis with more recently available microsatellite markers within the reported region showed heterozygosity with some of the new markers, and the crossovers lead to a refinement of the disease region from 21 to $11.53 \mathrm{cM}$. Mutation screening has excluded some of the candidate genes in the region. The disease phenotype of this family could be due to a mutation in a novel gene located within the refined CORD8 locus.
\end{abstract}

Electronic Supplementary Material Supplementary material is available to authorised users in the online version of this article at http://dx.doi.org/10.1007/s10038-006-0028-y.

Khalid Anwar: Deceased

M. Ismail · A. Abid · K. Anwar · S. Qasim Mehdi (凶) ·

S. Khaliq

Biomedical and Genetic Engineering Division,

Dr. A. Q. Khan Research Laboratories, GPO Box 2891,

25 Mauve Area, Islamabad 44000, Pakistan

e-mail: sqmehdi@comsats.net.pk
Keywords CORD8 $\cdot$ Phenotype $\cdot$ Cone-rod dystrophy $\cdot$ Visual acuity $\cdot$ Retinal dystrophy

\section{Introduction}

Cone-rod retinal dystrophies (CORD) are characterized by the simultaneous involvement of both cone and rod photoreceptor cells (Berson et al. 1968; Heckenlively 1987; Moore 1992). Patients are affected from an early age and there is a progressive loss of visual acuity and color vision followed by night blindness and loss of peripheral vision. Later in life, vision is often reduced to the bare perception of light. In the early stages, typical fundus changes are macular atrophy and pigmentation, which become widespread as the disease progresses. Genetic studies have so far identified seven loci for cone-rod dystrophies on chromosomes 17q (Klystra and Aylsworth 1993), 19q (Evans et al. 1994), 18q (Warburg et al. 1991), 17p13 (Balciuniene et al. 1995; Payne et al. 1999), 6q (Kelsell et al. 1998a), 1q12 (Khaliq et al. 2000) and 8p11 (Danciger et al. 2001). Mutations in the peripherin/RDS (Nakazawa et al. 1994), $C R X$ (Freund et al. 1997; Swain et al. 1997), RetGC-I (Kelsell et al. 1998b), ABCR (Cremers et al. 1998), CNGA3 (Wissinger et al. 2001), RPGRIP1 (Hameed et al. 2003) and SEMA4A (Abid et al. 2006) genes have been shown to cause both autosomal dominant and recessive cone-rod dystrophies.

We previously reported the mapping of an autosomal recessive CORD8 locus on chromosome 1q12-q24 in a consanguineous Pakistani family (Khaliq et al. 2000). The maximum LOD score, $Z=4.22$, was obtained for the marker D1S2635. Positive LOD scores 
ranging from 2.13 to 3.97 at $\theta=0.00-0.20$ were also obtained with several other markers. Recombination events defined the proximal and distal boundaries of the disease locus between markers D1S457 and D1S2681, respectively. All patients of the CORD8 family were homozygous for markers D1S498, D1S2635, D1S2771, D1S484 and D1S2768 that defined a very large region of approximately $21 \mathrm{cM}$. With the availability of several new markers in this region we have now refined the CORD8 critical disease interval to $11.53 \mathrm{cM}$. Important clinical observations are also reported in detail.

\section{Materials and methods}

One of the authors (KA) examined all of the patients and their unaffected family members (Fig. 1). Previous histories and clinical details were available for each patient from their childhood records. Fundoscopic examination using a Topcon (Tokyo, Japan) TRC 50× retinal camera was performed for all individuals affected. ERGs were recorded using LKC Technologies (Gaithersburg, MD, USA) EPIC 200 equipment.

For genotyping, polymorphic microsatellite markers were selected from the NCBI (http://www.ncbi.

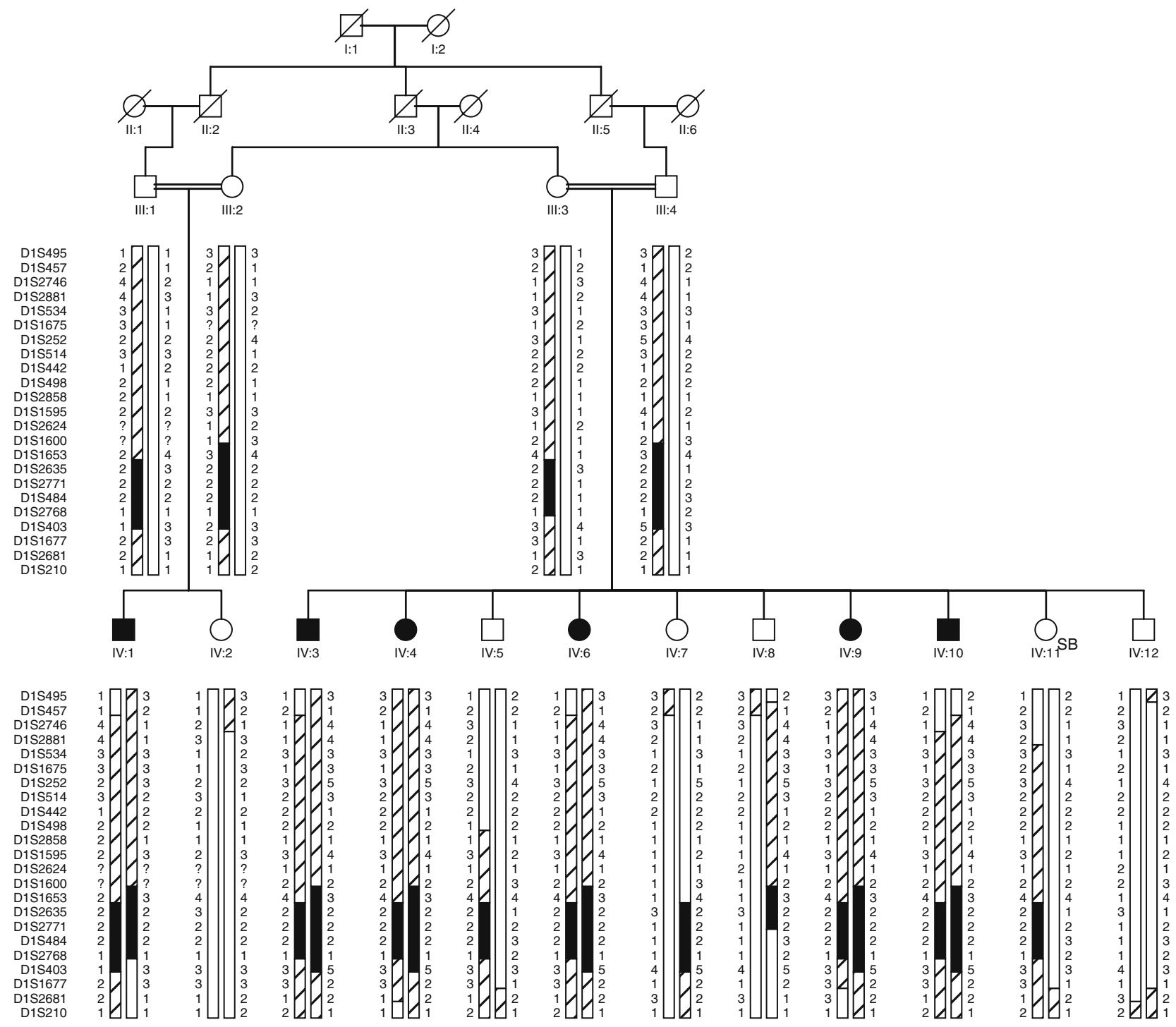

Fig. 1 Pedigree of the Pakistani autosomal recessive cone-rod dystrophy (CORD8) family with their genotypes. Filled symbols indicate affected individuals, open symbols indicate unaffected

individuals, hatched bars indicate disease chromosomes and filled regions indicate disease-associated haplotypes 
Table 1 Clinical details for the affected individuals in the Pakistani CORD8 family

\begin{tabular}{lllll}
\hline Subjects & IV:3 & IV:4 & IV:9 & IV:10 \\
\hline Age when examined (years) & 44 & 42 & 32 & 30 \\
Age of onset of disease (years) & $12-14$ & $12-16$ & $12-14$ & $12-15$ \\
Photophobia & +++ & ++ & +++ & +++ \\
Epiphora & +++ & +++ & +++ Since childhood & +++ \\
Loss of color vision & +++ Since childhood & +++ Since childhood & +++ Since childhood \\
Visual acuity & PL+ HM+ Both eyes & Right PL+ Left PL- & PL- Both eyes & Counting fingers \\
& & & & both eyes \\
Attenuation of arterioles & +++ & +++ & +++ & +++ \\
Ant. segment & Normal & Normal & Keratoconus & Cormal \\
Cornea & Clear & Clear & Poor & Lear than normal \\
Pupillary reaction & Sluggish & Less than normal & - & Not marked \\
Choroidal vessels sclerosis & Visible & - & +++ & + \\
Macular degeneration & +++ & ++ & Center+++ Periphery++ & Center++ \\
Pigmentary distribution & Center+++ & Center+++ & Periphery+ \\
Optic disc & Periphery++ & Periphery+++ & Pale and waxy & Pale and waxy \\
Cataract & Pale and waxy & Pale and waxy & Posterior subcapsular & -
\end{tabular}

$H M$ hand movements, $P L$ perception of light

nlm.nih.gov), GDB (http://www.gdb.org) and Marshmed (http://www.research.marshfieldclinic.org/genetics/ Map_Markers/maps/IndexMapFrames.html) genetic databases. Primers were synthesized for each microsatellite marker using an ABI 392 DNA/RNA synthesizer. Genomic DNA was amplified by polymerase chain reaction (PCR) and the products were separated on polyacrlyamide gels as described previously (Khaliq et al. 2000).

Mutation screening of the candidate genes HPRP3 and $S E M A 4 A$ in carriers was performed by direct DNA sequencing using the ABI377 DNA sequencer and the Prism Ready Reaction Sequencing Kit (PE$\mathrm{ABI})$. The sequences for specific SEMA4A gene primers used for mutation screening were the same as described previously (Abid et al. 2006). HPRP3 gene primer sequences are given in Table 1 of the supplementary material.

\section{Results and discussion}

The clinical details (Table 1)revealed that the affected individuals had been suffering from loss of color vision, severe photophobia and epiphora in bright light since childhood. They usually preferred to stay in dimly lit environments and had suffered from progressive deterioration of vision since childhood. However, vigorous deterioration in central vision started at the age of 12 and there was a rapid loss of vision between the ages of 14 and 16 years.

Visual acuity among the patients varied from the bare perception of light, hand movement and counting fingers to complete blindness. Figure $2 \mathrm{~A}-\mathrm{C}$ shows the representative fundus photographs of selected patients. They reveal a high degree of fundus granularity and marked macular degeneration. Significant levels of attenuated arterioles with bony corpuscle types of retinal pigment epithelium disturbances were observed in all patients. Macular degeneration with choroidal sclerosis was prominent in patient IV:3 (Fig. 2A). This patient had typical RP bony spicule pigmentation along with sever maculopathy in both eyes. Peripheral pigmentary changes in individual IV:4 (Fig. 2B) were web-shaped. Pigmentary changes in the peripheral area were less marked in individual IV:10 (Fig. 2C). The anterior segment was normal in all affected individuals except in IV:9, who had keratoconus in both eyes with central scarring around the apex of the keratoconus and corneal thinning at the apex (Fig. 2D). The optic discs were pale and waxy in appearance, but intraocular pressure was normal in all affected individuals. Both photopic and scotopic full-field ERG amplitudes were extremely low, demonstrating the involvement of both cone and rod photoreceptors.

In order to narrow down the disease region, various databases were searched in order to identify polymorphic microsatellite markers within the distal and proximal ends of the homozygosity region. Five polymorphic microsatellite markers (D1S2858, D1S1595, D1S2624, D1S1600 and D1S1653) were selected at the proximal end between markers D1S498 and D1S2635. Three markers (D1S2844, D1S403 and D1S1677) were selected at the distal end between D1S2768 and D1S2681. Crossovers at the proximal end between 
Fig. 2A-D Representative fundus photographs of affected individuals, IV:3 (A), IV:4 (B), IV:10 (C). Side view of the eye of individual IV:9 (D) showing cone shaped cornea (keratoconus)
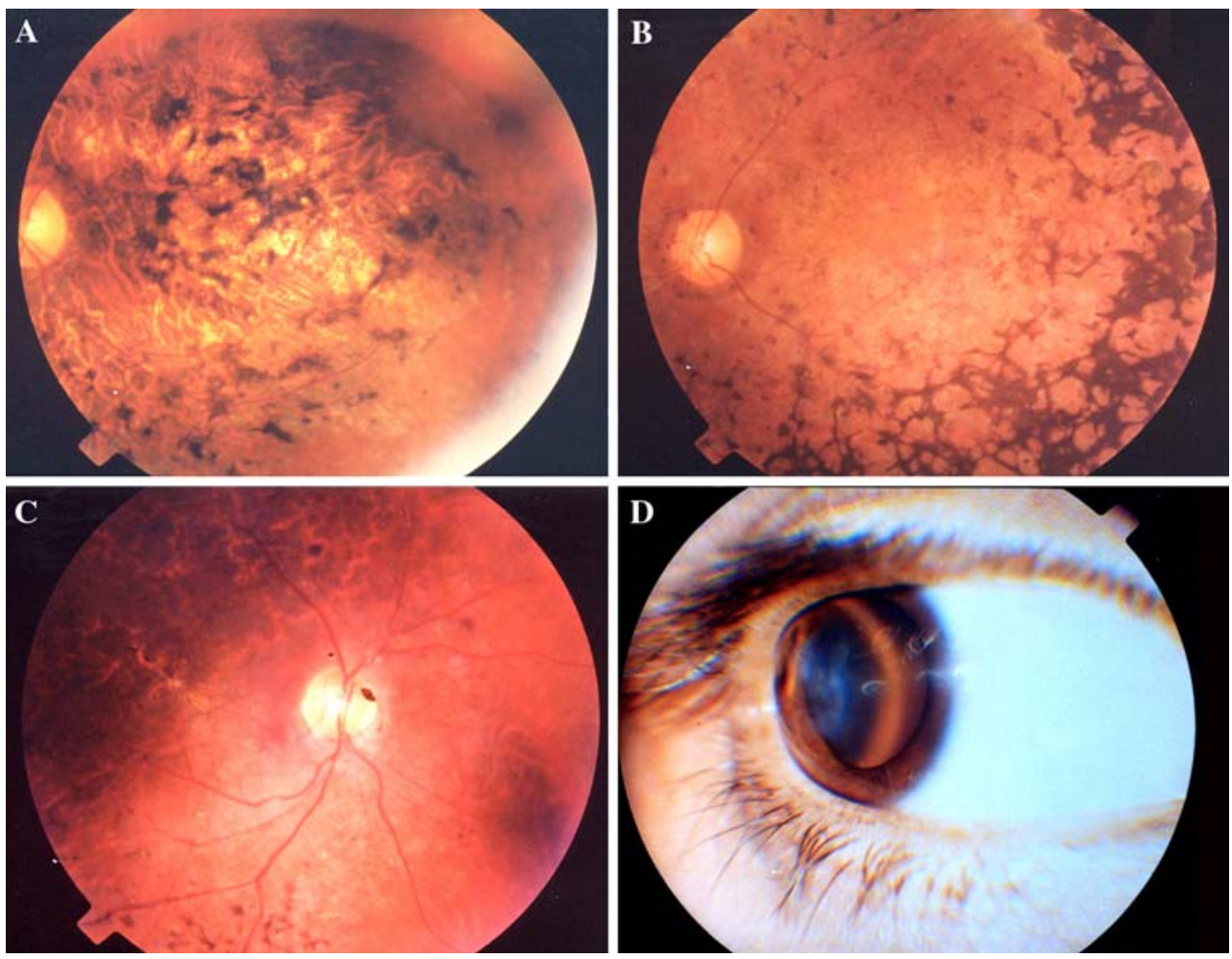

markers D1S1600 and D1S1653 led to a reduction of $9.73 \mathrm{cM}$, while crossovers at the distal end with marker D1S1677 resulted in a further reduction of $3.48 \mathrm{cM}$. Thus the new critical disease region for CORD8 is flanked by microsatellite markers D1S1653 and D1S403, reducing it from 21 to $11.53 \mathrm{cM}$.

It has recently been shown that mutations in Semaphorin (SEMA4A) are associated with retinal degenerative diseases including cone-rod dystrophies (Abid et al. 2006). Therefore, bidirectional DNA sequencing for mutation screening of $S E M A 4 A$ was performed using flanking intronic primers. No diseaseassociated gene mutation was found in SEMA4. Similarly, mutations in the human ortholog of the yeast premRNA splicing factor 3 (HPRP3) have been shown to cause retinitis pigmentosa 18 (RP18) [OMIM\#601414] (Chakarova et al. 2002) and this locus overlaps CORD8. Sequence analysis of HPRP3 did not show any change in the patients. Another three genes GNAT2, CRABP2 and KCNJ10 within and around the disease region were excluded in a previous study (Khaliq et al. 2000). This suggests that another novel gene in the refined region may be responsible for the disease.

Acknowledgments This work was supported by Wellcome Trust grant number 063406/Z/2000/Z to SQM. The authors thank the family members for taking part in this study. We also thank Dr. Q Ayub for his valuable help.

\section{References}

Abid A, Ismail M, Mehdi SQ Khaliq S (2006) Identification of novel mutations in SEMA4A gene associated with retinal degenerative diseases. J Med Genet 43:378-381

Balciuniene J, Johansson K, Sandgren O, Wachtmeister L, Holmgren G, Forsman K (1995) A gene for autosomal dominant progressive cone dystrophy (CORD5) maps to chromosome 17p12-p13. Genomics 30:281-286

Berson E, Gouras P, Gunkel R (1968) Progressive cone-rod degeneration. Arch Ophthalmol 80:68-76

Chakarova CF, Hims MM, Bolz H, Abu-Safieh L, Patel RJ, Papaioannou MG, Inglehearn CF, Keen TJ, Willis C, Moore AT, Rosenberg T, Webster AR, Bird AC, Gal A, Hunt D, Vithana EN, Bhattacharya SS (2002) Mutations in HPRP3, a third member of pre-mRNA splicing factor genes, implicated in autosomal dominant retinitis pigmentosa. Hum Mol Genet 11:87-92

Cremers FPM, van de Pol DJR, van Driel M, den Hollander AI, van Haren FJJ, Knoers NVAM, Tijmes N, Bergen AAB, Rohrschneider K, Blankenagel A, Pinckers AJLC, Deutman AF Hoyng CB (1998) Autosomal recessive retinitis pigmentosa and cone-rod dystrophy caused by splice site mutations in the Stargardt's disease gene ABCR. Hum Mol Genet 7:355-362

Danciger M, Hendrickson J, Lyon J, Toomes C, McHale JC, Fishman GA, Inglehearn CF, Jacobson SG, Farber DB (2001) CORD9 a new locus for arCORD: mapping to 8p11, estimation of frequency, evaluation of a candidate gene. Invest Ophthalmol Vis Sci 42:2458-2465

Evans K, Fryer A, Inglehearn C, Duvall-Young J, Whittaker JL, Gregory CY, Butler R, Ebenezer N, Hunt DM, Bhattacharya S (1994) Genetic linkage of cone-rod retinal dystrophy to chromosome $19 \mathrm{q}$ and evidence for segregation distortion. Nat Genet 6:210-213 
Freund CL, Gregory-Evans CY, Furukawa T, Papaioannou M, Looser J, Ploder L, Bellingham J, Herbrick JAS, Duncan A, Scherer SW, Tsui LC, Loutradis-Anagnostou A, Jacobson SG, Cepko CL, Bhattacharya SS, McInnes RR (1997) Conerod dystrophy due to mutations in a novel photoreceptorspecific homeobox gene (CRX) essential for maintenance of the photoreceptor. Cell 91:543-553

Hameed A, Abid A, Amtul-Aziz, Ismail M, Mehdi SQ, Khaliq S (2003) Evidence of RPGRIP1 gene mutations associated with recessive cone-rod dystrophy. J Med Genet 40:616-619

Heckenlively JR (1987) RP cone-rod degeneration. Trans Am Ophthalmol Soc 85:438-470

Kelsell RE, Gregory-Evans K, Gregory-Evans CY, Holder GE, Jay MR, Weber BHF, Moore AT, Bird AC, Hunt DM (1998a) Localization of a gene (CORD7) for a dominant cone-rod dystrophy to chromosome 6q. Am J Hum Genet 63:274-279

Kelsell RE, Gregory-Evans K, Payne AM, Perrault I, Kaplan J, Yang RB, Garbers DL, Bird AC, Moore AT, Hunt DM (1998b) Mutations in the retinal guanylate cyclase (RETGC-1) gene in dominant cone dystrophy. Hum Mol Genet 7:1179-1184

Khaliq S, Hameed A, Ismail M, Anwar K, Leroy BP, Mehdi SQ, Payne AM, Bhattacharya SS (2000) Novel locus for autosomal recessive cone-rod dystrophy CORD8 mapping to chromosome 1q12-q24. Invest Ophthalmol Vis Sci 41:37093712

Klystra JA, Aylsworth AS (1993) Cone-rod retinal dystrophy in a patient with neurofibromatosis type 1 . Can J Ophthalmol 28:79-80
Moore AT (1992) Cone and cone-rod dystrophies. J Med Genet 29:289-290

Nakazawa M, Kikawa E, Chida Y, Tamai M (1994) Asn244His mutation of the peripherin/RDS gene causing autosomal dominant cone-rod degeneration. Hum Mol Genet 3:11951196

Payne AM, Khaliq S, Hameed A, Ismail M, Bessant DAR, Mehdi SQ, Bhattacharya SS (1999) A Gene for autosomal recessive cone-rod dystrophy maps to chromosome $17 \mathrm{p} 12$ 13. Am J Hum Genet 65:2490

Swain PK, Chen SM, Wang QL, Affatigato LM, Coats CL, Brady KD, Fishman GA, Jacobson SG, Swaroop A, Stone E, Sieving PA, Zack DJ (1997) Mutations in the cone-rod homeobox gene are associated with the cone-rod dystrophy photoreceptor degeneration. Neuron 19:1329-1336

Warburg M, Sjo O, Tranebjaerg L, Fledelius HC (1991) Deletion mapping of a retinal cone-rod dystrophy assignment to 18q211. Am J Med Genet 39:288-293

Wissinger B, Gamer D, Jagle H, Giorda R, Marx T, Mayer S, Tippmann S, Broghammer M, Jurklies B, Rosenberg T, Jacobson SG, Sener EC, Tatlipinar S, Hoyng CB, Castellan C, Bitoun P, Andreasson S, Rudolph G, Kellner U, Lorenz B, Wolff G, Verellen-Dumoulin C, Schwartz M, Cremers FP, Apfelstedt-Sylla E, Zrenner E, Salati R, Sharpe LT, Kohl S (2001) CNGA3 mutations in hereditary cone photoreceptor disorders. Am J Hum Genet 69:722-737 